\title{
Traumatic injury of the pulmonary artery: Transection, rupture, pseudoaneurysm, or dissection? Sometimes semantics do matter
}

\author{
Abbas E. Abbas, MD, MS, FACS
}

\footnotetext{
From the Division of Thoracic Surgery, Department of Thoracic Medicine and Surgery, Lewis Katz School of Medicine at Temple University, Philadelphia, Pa.

Disclosures: A.E.A. is a paid consultant for Boston Scientific, Inc, and Intuitive Surgical, Inc. Neither entity was involved in the preparation of this editorial.

Received for publication July 3, 2016; accepted for publication July 6, 2016; available ahead of print Aug 26, 2016.

Address for reprints: Abbas E. Abbas, MD, MS, FACS, Department of Thoracic Medicine and Surgery, Temple University Health System, Lewis Katz School of Medicine, 3401 N Broad St, Suite C-100, Philadelphia, PA 19035 (E-mail: abbas.abbas@temple.edu).

J Thorac Cardiovasc Surg 2016;152:1437-8

$0022-5223 / \$ 36.00$

Copyright (C) 2016 by The American Association for Thoracic Surgery

http://dx.doi.org/10.1016/j.jtcvs.2016.07.019
}

No other vessel commands the respect of a thoracic surgeon as much as the pulmonary artery (PA) does. Transection or rupture of even a small branch can cause fatal exsanguination in seconds, and yet it can also be easily controlled with gentle compression. Both of these characteristics are due to the low pressure in the PA circulation and to the thin, compliant nature of the wall of the PA.

A pseudoaneurysm may form when reepithelialization of the perforation does not occur, and delayed rupture can occur even months later., ${ }^{1,2}$ A pseudoaneurysm may stabilize and resolve or expand and rupture, depending on etiology, size, and intravascular pressure. In 1963, Symbas and $\mathrm{Scott}^{3}$ described how larger pseudoaneurysms tended to bleed, whereas smaller ones often went undetected.

The most common cause of PA ruptures and pseudoaneurysms is PA catheters. ${ }^{1,2,4,5}$ With the decreased use of PA catheters and the ubiquitous use of computed tomographic scans for trauma patients, however, the incidence of traumatic pseudoaneurysms has increased. ${ }^{3,6-17}$

Traumatic PA dissections (PADs) have also been described. ${ }^{18-20}$ The mechanism is likely similar to that seen in the aorta as a result of shearing forces and differential deceleration of the mediastinum and the spine. Traumatic PADs will usually resolve or remain stable unless associated with pulmonary hypertension, in which case the risk of bleeding may be quite high. ${ }^{18-20}$

Management of traumatic PA injuries includes surgical repair, endovascular approaches, and observation. There are no strict guidelines, and the preferred approach depends on the lesion, the patient, and the institution. Currently, the standard treatment for pseudoaneurysms is endovascular placement of coils or plugs in or adjacent to the pseudoaneurysm or into the artery feeding it. ${ }^{21}$ Surgical repair may be considered when the endovascular measures fail or are not feasible and is the only option for acute rupture

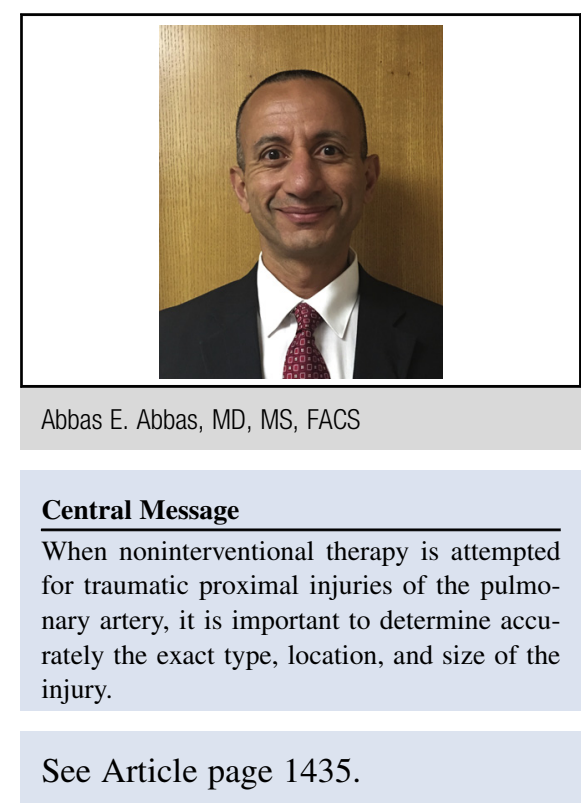

or tamponade. For intraparenchymal pseudoaneurysms, surgical ligation and lung resection may be possible. For a proximal PA injury, however, it is necessary to use cardiopulmonary bypass during the repair of the lesion. Conservative management with close clinical and imaging surveillance is recommended for asymptomatic lesions smaller than $2 \mathrm{~cm}$ and for PADs. $5,12,22,23$

In this issue of the Journal, Demondion and colleagues ${ }^{24}$ describe a case of a deceleration injury of the intrapericardial right PA that was successfully managed conservatively. Because of the associated intracranial injury, anticoagulation for cardiopulmonary bypass was contraindicated. The intrapericardial location made it hazardous to attempt transcatheter approaches because of the high risk of rupture and tamponade. PA stenting, which was initially considered, may not have been ideal for this angular vessel. In adults it is difficult to introduce a large stent device through both the tricuspid and pulmonary valves and into the right PA.

Demondion and colleagues ${ }^{24}$ conclude that for acute pulmonary artery "transection" after blunt trauma, an initial conservative management strategy must be considered when anticoagulation is contraindicated. Of course, such a course would not be possible in cases of true transection. It may indeed be reasonable, however, for most cases of small and asymptomatic traumatic pseudoaneurysms or PADs. When 
noninterventional therapy is attempted, one must ensure the absence of bleeding, because even minor intrapericardial hemorrhage can presage fatal tamponade. It is also important to accurately determine the exact location, size, and type of the injury, because in this disease, semantics do matter.

\section{References}

1. Evans DC, Doraiswamy VA, Prosciak MP, Silviera M, Seamon MJ, Rodriguez Funes V, et al. Complications associated with pulmonary artery catheters: a comprehensive clinical review. Scand J Surg. 2009;98:199-208.

2. DeLima LG, Wynands JE, Bourke ME, Walley VM. Catheter-induced pulmonary artery false aneurysm and rupture: case report and review. J Cardiothorac Vasc Anesth. 1994;8:70-5.

3. Symbas PN, Scott HW Jr. Traumatic aneurysm of the pulmonary artery. J Thorac Cardiovasc Surg. 1963;45:645-9.

4. McQueen AS, Mitchell L, Muller M, MacGowan G, Corris P. Iatrogenic pulmonary artery pseudoaneurysm: Images from different modalities. Thorax. 2008;63:938.

5. You CK, Whatley GS. Swan-Ganz catheter-induced pulmonary artery pseudoaneurysm: a case of complete resolution without intervention. Can J Surg. 1994;37:420-4.

6. Abreu AR, Campos MA, Krieger BP. Pulmonary artery rupture induced by a pulmonary artery catheter: a case report and review of the literature. J Intensive Care Med. 2004;19:291-6.

7. el-Fiky M. Traumatic closed complete and partial rupture of the main bronchi accompanied with closed rupture of main pulmonary artery: a critical analysis and review of the literature. J Egypt Med Assoc. 1977;60:243-55.

8. Clements RH, Fischer PJ II. Blunt injury of the intrapericardial great vessels. J Trauma. 2001;50:129-31.

9. Clements RH, Wagmeister LS, Carraway RP. Blunt intrapericardial rupture of the pulmonary artery in a surviving patient. Ann Thorac Surg. 1997;64:258-60.

10. Collins MP, Robinson GC. Traumatic rupture of the pulmonary artery. Ann Thorac Surg. 1989;47:612-3.

11. Gjoeres JE. Traumatic rupture of the pulmonary artery. Acta Chir Scand. 1964; $127: 173-5$.
12. Goel S, Kumar A, Gamanagatti S, Gupta A. Spontaneous resolution of posttraumatic pulmonary artery pseudoaneurysm: report of two cases. Lung India. 2013;30:203-5.

13. Hanline MH Jr. Blunt traumatic rupture of the main pulmonary vessels. South Med J. 1983;76:541-2.

14. Melloni G, Casiraghi M, Nicoletti R, Zannini P. Post-traumatic intrapulmonary rupture of the pulmonary artery. Eur J Cardiothorac Surg. 2005;28:165.

15. Pereira SJ, Narrod JA. Repair of right pulmonary artery transection after blunt trauma. Ann Thorac Surg. 2009;87:939-40.

16. Riquet M, Dujon A, Lahsoune A, Molinier H. Traumatic rupture of the middle lobe bronchus and pulmonary artery: considerations apropos of a case. J Chir (Paris). 1985;122:183-5.

17. Sridhar SK, Sadler D, McFadden SD, Ball CG, Kirkpatrick AW. Percutaneous embolization of an angiographically inaccessible pulmonary artery pseudoaneurysm after blunt chest trauma: a case report and review of the literature. J Trauma. 2010;69:729.

18. Almdahl SM, Jakobsen $\varnothing$, Skattør TH. Dissection of the right pulmonary artery after blunt trauma. Eur J Cardiothorac Surg. 2014;46:141-2.

19. Chung JH, Mullins CD, Manchanda V, Gunn ML, Stern EJ. Pulmonary artery intimal injury associated with blunt trauma. Emerg Radiol. 2009;16: 497-9.

20. Navas Lobato MA, Martín Reyes R, Lurueña Lobo P, Maté Benito I, Guzmán Hernández G, Martí de Gracia M, et al. Pulmonary artery dissection and conservative medical management. Int J Cardiol. 2007;119:e25-6.

21. Karak P, Dimick R, Hamrick KM, Schwartzberg M, Saddekni S. Immediate transcatheter embolization of Swan-Ganz catheter-induced pulmonary artery pseudoaneurysm. Chest. 1997;111:1450-2.

22. Rouquier J, Arrive L, Masini JP, Monnier-Cholley L, Lewin M, Tubiana JM. Spontaneous resolution of asymptomatic false aneurysm of the pulmonary artery induced by Swan-Ganz catheter. J Radiol. 2001;82: 1732-4.

23. Biswas M, Boruah PK, Koch LV. A conservative surgical approach for management of iatrogenic pulmonary artery perforation. Indian J Crit Care Med. 2012; 16:157-9.

24. Demondion P, Bellemare P, El-Hamamsy I. Conservative management of an intra-pericardial contained rupture of the right pulmonary artery in blunt trauma: a good idea? J Thorac Cardiovasc Surg. 2016;152:1435-6. 